\title{
Positive Emotions in Volunteerism
}

\author{
María Luisa Vecina Jiménez and Fernando Chacón Fuertes \\ Complutense University Madrid
}

\begin{abstract}
Volunteerism is a well consolidated social phenomenon in our society. However, its rapid growth in the last few years has complicated the integration of theoretical knowledge and its application in organizational settings. Taking into account that nowadays, one of the chief problems of volunteer organizations is sustained volunteer service, the object of this work is to verify, within the context of the psychosocial model of sustained volunteerism (Vecina, 2001), the type of relation between the experience of positive emotions in volunteers and their intention of remaining in the organization. This work was carried out on a sample of volunteers who had been in service for less than one year prior to this study.
\end{abstract}

Keywords: volunteerism, positive emotions, sustained service

El voluntariado es un fenómeno social ya consolidado en nuestra sociedad. Sin embargo, el rápido crecimiento que en los últimos años ha experimentado hace difícil la integración de conocimientos teóricos y su aplicación en los contextos organizacionales. Considerando que uno de los principales problemas que tienen las organizaciones de voluntariado actualmente es la permanencia de su voluntariado, el objetivo de este trabajo es constatar, dentro del contexto aportado por el modelo psicosocial de la permanencia del voluntariado (Vecina, 2001), el tipo de relación existente entre la experiencia de emociones positivas en el voluntariado y la intención de permanencia en la organización en una muestra de voluntarios que lleva menos de un año de permanencia previa.

Palabras clave: voluntariado, emociones positivas, permanencia

Correspondence should be addressed to María Luisa Vecina, Facultad de Psicología, Universidad Complutense de Madrid. Campus de Somosaguas, 28223 Madrid (Spain). E-mail: mvecina@psi.ucm.es

Translation: Virginia Navascués Howard 
Volunteerism is currently in the framework of formally constituted non-profit organizations, both because of criteria of efficacy and utility and ethical views of social problems. There is a growing demand for the professionalization of its management systems.

From all the spheres of society, it has been stated that in order to achieve the best ends, the best means must be made available. This means substituting the notion of the volunteer as a person who has good will with a more professional concept, in accordance with the idea that good will does not automatically guarantee good results. Making the best means available in order to achieve the best ends involves, on the one hand, professionalization of the internal management systems of the organizations so that the desired results are achieved at the lowest possible cost. On the other hand, it also requires professionalization of volunteer involvement, because volunteers are crucial for the efficient accomplishment of organizational goals, and their more or less sustained service has direct consequences both on the users and on the organization.

However, the criteria of efficiency and utility, demandable in this process as they guarantee the quality of the services or activities carried out with regard to third parties, should be accompanied by activities that tend to increase volunteer satisfaction; otherwise, one would be fomenting their illicit use. To increase volunteer permanence by affecting volunteer satisfaction is a formula that respects the many differences that distinguish the professionals - who have an instrumental commitment and whose permanence is guaranteed by means of a work contract-from the volunteers-whose commitment is related to ethical and emotional aspects.

Within this interpretative framework, a leading role can be assigned to positive emotions, because developing and encouraging this type of experiences in volunteers is a legitimate way to keep up their desire to be involved with the organization and hence, to guarantee a minimal stability in the programs they carry out.

The psychosocial model of sustained volunteerism (Chacón \& Vecina, 2002; Vecina, 2001) provides important empirical data that support this proposal. This model establishes that the main predictor of volunteer permanence in an organization is the volunteers' own intention of remaining in service when they appraise those aspects that are under their control. In turn, the intention of remaining in service is accounted for by volunteers' previous service duration in the organization, the conflict within the organization, and volunteer satisfaction when performing their tasks. Lastly, volunteer satisfaction is accounted for

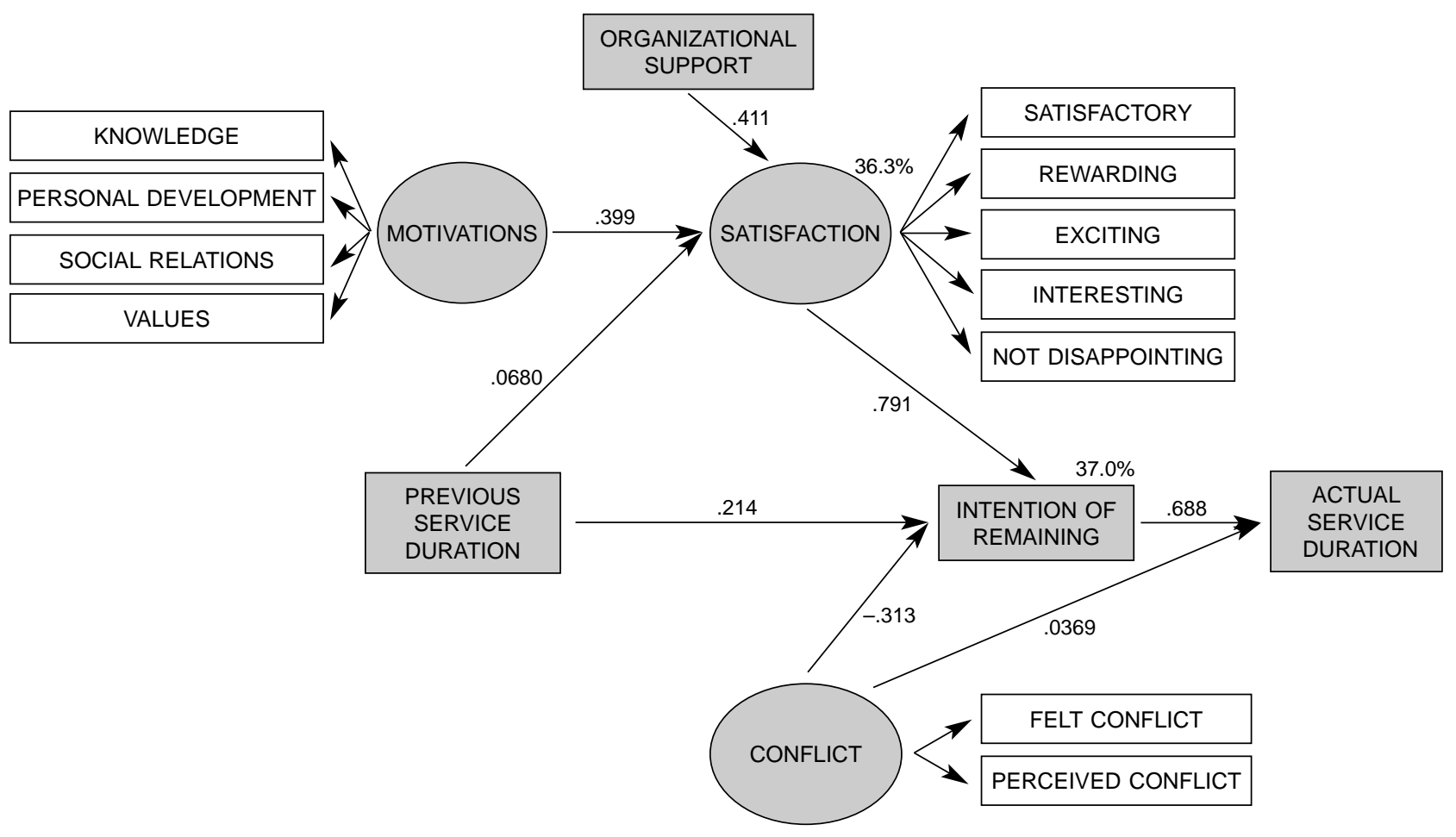

Figure 1. Psychosocial Model of Sustained Volunteerism (Vecina, 2001). 
by their motivations and by the emotional support provided by the organization. This model (see Figure 1) allocates an important role to volunteer satisfaction when attempting to increase service longevity. It is therefore an appropriate setting from which to explore the utility of positive emotions in volunteerism.

Although the definition of emotions is still a topic of debate (Diener, 1999; Ekman \& Davidson, 1994), some consensus seems to be emerging about a few basic characteristics (Fredrickson, 2001). Emotions can thus be considered response tendencies with high adaptive value, with obvious manifestations at the physiological level, in facial expression, subjective experience, information processing, etc., that are intense but short-lived and that occur when some antecedent event is appraised.

This basic definition, which is doubtless an important improvement in the study of emotions, seems more appropriate for the study of negative emotions such as fear, anxiety, anger, and so forth than for the study of positive emotions such as joy, pride, hope, and so on. When persons feel afraid of something or someone, their alert systems become activated, they quickly prepare to flee or to protect themselves, and their face reflects a unique expression, which is practically universally recognized by any individual. The emission of such responses very probably allows individuals to save their lives in numerous situations (immediate direct benefit), which shows the survival value of negative emotions. However, when people experience joy, the response tendency is less specific and longer lasting: The person may jump for joy, or start to fool around, help others, make plans for the future, play, explore, and so forth. The survival value of this kind of response for the individual does not seem so evident, particularly because it is not immediate.

Barbara Fredrickson (1998) and her colleagues (Fredrickson \& Branigan, 2000; Fredrickson \& Joiner, 2002; Fredrickson \& Levenson, 1998) have been working with positive emotions and their adaptive value within the framework of positive psychology (Seligman, 2002). They start out with the notion that positive emotions bring about important benefits to people and, although these benefits are more indirect than those provided by negative emotions, they are longer lasting. Concretely, these authors proposed that positive emotions such as joy, enthusiasm, satisfaction, pride, love, etc., although phenomenologically different from each other, share the characteristic of permanently expanding people's thought and action repertoires as well as their physical, psychological, and social resources, so that these resources will become part of a stock that will be available for future moments of crisis.

To experience positive emotions is always enjoyable and pleasant at the short term, but beyond that, it has other beneficial effects. In this sense, current empirical evidence shows that the experience of positive emotions increases the likelihood of feeling good in the future (Fredrickson, 1998), it makes people more resistant to adversity (Carver,
1998; Lazarus, 1993), it facilitates establishing relations of friendship and love, which may later on lead to forming social support networks, coalitions, etc. that are very beneficial in situations of conflict or scarcity (Fredrickson, 1998). Positive emotions also seem to undo the physiological effects caused by negative emotions; That is, the experience of positive emotions is associated with lower cardiovascular activity and, therefore, less damage to the system (Fredrickson \& Levenson, 1998).

Although most situations that involve individuals in our society are fortunately no longer matters of life and death, it is nonetheless noteworthy and very useful to study in depth the long- and short-term benefits of the frequent experience of positive emotions.

In the specific area of volunteerism, we expect the study of positive emotions to be interesting and very valuable for managing programs that explore the relation between positive emotions and the intention of remaining in service. Cnaan and Cascio (1999) indicated in their conclusions that to experience a feeling of pride in the work performed (an example of positive emotion) could be a good predictor of volunteer satisfaction, commitment, and longevity of service in organizations.

Conversely, as many studies indicate, it is more likely for people to help when they feel happy than when they feel unhappy (Isen \& Levin, 1972; Cunningham, 1979; Wilson, 1981). It seems that when people feel happy, they concentrate less on themselves, they like other people more, and they even want to share their good luck with strangers (Seligman, 2002). We expect that such experiences play an important role both when deciding to join a volunteer organization and deciding to remain in it. Precisely, flow, a positive emotional state described by Csikszentmihalyi (1990), may play an important role in the decision to remain in an organization, because to experience total involvement in an activity is so pleasant that it leads people to continue to perform the activity despite the costs and the presence of obstacles. This type of experience occurs when people focus their attention on achieving realistic goals, when their skills match the performance opportunities, and when they obtain immediate feedback. A colloquial expression that describes this state is, "Time just flew by when I was doing..."

In this work, we will analyze the presence of positive emotions in a sample of socio-assistantial volunteers and relate these emotions to the volunteers' intention of remaining in the organization. We hypothesize significant and positive relations between the five items employed to evaluate the presence of positive emotions in the volunteers and their intention of remaining in service at short, mid, and long term. Taking the five items as a sole measurement of positive emotions experienced during various aspects of volunteerism, we also hypothesize that positive emotions will be a significant predictor of the intention of remaining in service at short, mid, and long term. 
Method

\section{Participants}

The sample was made up of a total of 109 volunteers, belonging to 26 different organizations, who carried out very diverse tasks within the socio-assistantial area and who had been in the organization for less than a year. Women comprised $72 \%$ of the sample, and the remaining $28 \%$ was made up of men. Participants' mean age was 30 years old $(S D=12.82)$, ranging between 17 and 68 years, and their mean previous service duration in the organization was 6.3 months $(S D=2.71)$.

\section{Instruments}

Positive Emotions Questionnaire. In order to measure positive emotions, an author-designed instrument was used, made up of 5 items (rated on a 1-7 point Likert scale). This instrument measured the experience of positive emotions about the organization to which the volunteer belonged and about the volunteer's role in the organization. Examples of positive emotions are: pride at belonging to a certain organization, happiness and enthusiasm about having chosen a certain organization and about performing volunteer work in it, the hopes of being able to achieve a better world by volunteerism, and flow, or the state of total involvement in the task performed. The reliability of the instrument administered to the sample of volunteers was satisfactory, especially taking into account that the instrument only has 5 items (Cronbach's $a=.779$ ).

Table 1

Means and Standard Deviations of the Variable Intention of Remaining in Service at Short, Mid, and Long Term

\begin{tabular}{lcc}
\hline Intention of Remaining in Service & $M$ & $S D$ \\
\hline At 6 months & 5.98 & 1.48 \\
At 1 year & 5.37 & 1.67 \\
At 2 years & 4.52 & 1.90 \\
\hline
\end{tabular}

Note. Scores ranged from 1-7, where 1 indicated no likelihood of remaining in service and 7 indicated maximum likelihood.
Intention of remaining in service. The variable intention of remaining in service was measured with 3 items. Each item asked the volunteers to rate, on a 1-7 point scale the likelihood $(1=$ none, $7=$ maximum $)$ of continuing with their volunteer activities within the organization at 6 months, at 1 year, and at 2 years.

\section{Procedure}

The questionnaires were completed voluntarily by volunteers of 26 organizations from the area of the Community of Madrid and returned by prepaid mail. Anonymity was guaranteed. All the measurements of this study were taken at the same time.

\section{Data analysis}

We calculated the correlations between the variables object of the study: positive emotions and the intention of remaining in service and subsequently estimated a simple regression equation to establish the predictive power of the positive emotions variable on the intention of remaining in service. The SPSS version 12.0 statistical package was employed to perform the statistical analyses. At an alpha level of .05 , the estimated power of a correlation of .30 in a sample of 109 subjects is $90 \%$.

\section{Results}

Volunteers' mean global score of positive emotions was high on the 1-7 point Likert scale $(M=5.85, S D=.87)$.

In Table 1 can be seen the mean scores and standard deviations of the variable intention of remaining in service at short, mid, and long term.

Correlational analysis revealed significant correlations between the measurement of positive emotions and the intention of remaining in the organization at 6 months, at 1 year, and at 2 years $(r=.489, r=.517, r=.485$, respectively, at $a=.000$ for all three). The correlations of between each of items measuring positive emotions and intention of remaining in service are shown in Table 2.

Table 2

Correlations between Positive Emotions and the Intention of Remaining in Service at Short, Mid, and Long Term

\begin{tabular}{|c|c|c|c|}
\hline \multirow{2}{*}{ Positive Emotions } & \multicolumn{3}{|c|}{ Intention of Remaining in Service } \\
\hline & At 6 months & At 1 year & At 2 years \\
\hline When I am performing my volunteer tasks, time just flies by. & $.412 * *$ & $.290 * *$ & $.239 *$ \\
\hline I think that it is possible to achieve a better world by volunteerism. & $.399 * *$ & $.358 * *$ & $.331 * *$ \\
\hline I am proud to be able to say that I belong to this organization. & $.290 * *$ & $.275^{* *}$ & $.286^{* *}$ \\
\hline This organization really brings out the best in me when performing my volunteer activity. & $.286^{* *}$ & $.394 * *$ & $.390 * *$ \\
\hline I am very happy to have chosen this organization in which to collaborate as a volunteer. & $.341 * *$ & $.497 * *$ & $.441 * *$ \\
\hline
\end{tabular}

$* p<.05 . * * p<.01$. 
All the items that measure the presence of positive emotions in the volunteers had significant and considerably high correlations with the intention of remaining in service at 6 months, at 1 year, and at 2 years. Specifically, we observed that one of the highest correlations occurred between the experience of flow and the short-term intention of remaining in the organization $(r=.412)$. The item used to measure flow ("when I am performing my volunteer tasks, time just flies by") corresponds to one of the most frequent descriptions reported by people who experience flow. Therefore, this can be interpreted in the sense that when volunteers do what they want to do, concentrate their entire attention on the task, make use of the necessary skills, and obtain constant feedback about their performance, then they express a clear intention of remaining in the organization at short term. The experience of flow is directly related to task performance in the present and, understandably, this has a higher correlation with the intention of remaining in service at short term than at long term.

Conversely, we also observed that to experience happiness and satisfaction for having chosen a certain volunteer organization instead of another also had a positive correlation with the intention of remaining at 1 year and at 2 years ( $r=.497$ and $r=.441$, respectively) and a lower correlation with the intention of remaining at 6 months. Therefore, satisfaction about making good choices seems to have a long-term rather than an immediate effect.

In order to calculate the predictive power of the variable positive emotions on the intention of remaining in service at 6 months, at 1 year, and at 2 years, three simple regression analyses were performed.

Regarding the short-term intention of remaining in service, the results showed that the variable positive emotions is a significant predictor of the intention of remaining of remaining in service at 6 months, $F(1)=31.094, p-.001$. The standardized regression coefficient $\beta$ was $.489, t=5.576$, $p=.000$, and the adjusted $R$ squared reached the value of .231 , indicating that the variable positive emotions accounts for $23 \%$ of the variance of the dependent variable intention of remaining in service at 6 months.

The results concerning the intention of remaining in service at 1 year and at 2 years were similarly significant, $F(1)=35.009, p-.001, \beta=.517$, adjusted $R^{2}=.260$, and $F(1)=29.276, p-.001, \beta=.485$, adjusted $R^{2}=.228$, for 1 year and 2 years, respectively.

\section{Conclusions}

Up till now, positive emotions in the sphere of volunteerism have not been explored and, as shown in this study, they seem to be highly related to sustained volunteer service. Although a correlation between two variables does not in any sense mean that causality can be deduced, the correlational data presented above do allow one to intuit the usefulness of positive emotions for increasing the intention of service duration. The simple regression analysis subsequently performed supports this notion, establishing that the conjoint measurement of positive emotions is a significant predictor of the intention or remaining in service. Although the percentage of variance accounted for is not very high in absolute terms (23\%), if one takes into account that sustained volunteerism is a phenomenon that is determined by multiple psychological, social, and organizational factors, such a percentage, provided by just one variable, can be considered sufficient.

To influence sustained service duration through satisfaction is undoubtedly a legitimate formula because it respects the voluntariness and gratuity of all volunteer action. It is also operative from the organizational viewpoint because it allows one to manipulate many organizational aspects in order to increase volunteer satisfaction.

In this sense, managers of volunteer programs may enhance the experience of volunteers' positive emotions in many ways, for example, adjusting the tasks to be performed with the volunteers' concerns, skills, and motivations (nothing is more gratifying than doing what one wants to do), lending meaning to the tasks, because to perceive that the tasks that one carries out are necessary and useful to achieve desired goals gives them meaning. Another way is to arrange challenges, acknowledging and valuing initiatives, reinforcing and appreciating the efforts made and the work well done, especially routine work; in short, enhancing the use of each volunteer's potential. When the managers of an organization believe in the work carried out by the organization, are aware that the organization needs other people to fulfill its mission, they take care of and admire the volunteers, then it is highly likely that the organization will generate satisfaction, pride, hope, enthusiasm, flow, etc., in the volunteers.

Future works should study these aspects in depth, verifying the relation between positive emotions and real service duration in the organizations. For this purpose, longitudinal studies are required.

\section{References}

Carver, C.S. (1998). Resilience and thriving: Issues, models, and linkages. Journal of Social Issues, 54, 245-266.

Chacón, F., \& Vecina, M.L. (2002). Gestión de programas de voluntariado. Madrid: Síntesis.

Cnaan, R., \& Cascio, T. (1999). Performance and commitment: Issues in management of volunteers in human service organizations. Journal of Social Service Research, 24, 1-37.

Csikszentmihalyi, M. (1990). Flow: The psychology of optimal experience. New York: Guilford Press.

Cunningham, M.R. (1979). Weather, mood, and helping behavior: Quasi-experiments with the sunshine Samaritans. Journal of Personality and Social Psychology, 50, 925-935.

Diener, E. (1999). Introduction to the special section on the structure of emotion. Journal of Personality and Social Psychology, 76, 803-804. 
Ekman, P., \& Davidson, R.J. (Eds.). (1994). The nature of emotion: Fundamental questions. New York: Oxford University Press. Fredrickson, B.L. (1998). What good are positive emotions? Review of General Psychology, 2, 300-319.

Fredrickson, B.L. (2001). The role of positive emotions in positive psychology: The broaden and build theory of positive emotions. American Psychologist, 56, 218-226.

Fredrickson, B.L., \& Branigan, C.A. (2000). Positive emotions. In T.J. Mayne \& G.A. Bonnano (Eds.), Emotion: Current issues and future directions (pp. 123-151). New York: Guilford Press.

Fredrickson, B.L., \& Joiner, T. (2002). Positive emotions trigger upward spirals toward emotional well-being. Psychological Science, 13, 172-175.

Fredrickson, B.L., \& Levenson, R.W. (1998). Positive emotions speed recovery from the cardiovascular sequelae of negative emotions. Cognition and Emotion, 12, 191-220.
Isen, A.M., \& Levin, P.A. (1972). Effect of feeling good and helping: Cookies and kindness. Journal of Personality and Social Psychology, 21, 384-388.

Lazarus, R.S. (1993). From psychological stress to the emotions: A history of changing outlooks. Annual Review of Psychology, 44, 1-22.

Seligman, M. (2002). Authentic happiness. New York: Free Press. Vecina, M.L. (2001). Factores psicosociales que influyen en la permanencia del voluntariado. Unpublished doctoral dissertation. Complutense University of Madrid.

Wilson, D.W. (1981). Is helping a laughing matter? Psychology, 18, 6-9.

Received: October 26, 2004

Revision received December 15, 2004

Accepted January 7, 2005 